\title{
Um convite de Allah: experiência etnográfica de uma pesquisadora no campo das religiões
}

\section{An invitation of allah: ethnographic experience of a researcher in the field of religions}

\author{
Vivian Fukumasu da Cunha ${ }^{1}$, Francirosy Campos Barbosa ${ }^{2}$, \\ Fabio Scorsolini-Comin ${ }^{3}$
}

\section{Resumo}

\begin{abstract}
A etnografia é uma metodologia qualitativa que busca apreender a maneira de viver e as experiências das pessoas, o que pode beneficiar as pesquisas em torno da religiosidade/espiritualidade $(R / E)$ em comunidades de referência. $\mathrm{O}$ objetivo deste estudo foi narrar uma experiência etnográfica de uma pesquisadora da área de R/E em visita a uma mesquita localizada no interior do Estado de São Paulo, discutindo suas impressões e diálogos com seu próprio campo empírico. As estratégias metodológicas utilizadas foram a observação direta e o diário de campo. A experiência etnográfica narrada pode ser útil para adentrar uma realidade de modo a evitar generalizações à primeira vista, exprimindo-a a partir da lente descritiva do pesquisador, de modo a articulá-la com conhecimentos existentes e/ou produzir novos. Em diálogo com a etnopsicologia, destacou-se a importância de manter uma postura de alteridade indispensável, a fim de compreender o universo religioso dos muçulmanos e refletir sobre como a R/E está presente em suas experiências pessoais e comportamentos. Por fim, considera-se que a etnografia não é fruto de uma ida a campo, mas de várias idas e vindas a campo, aos textos e aos diversos universos implicados, no entanto, esse exercício é fundamental ao pesquisador no campo da R/E.
\end{abstract}

Palavras-chave: Religião. Espiritualidade. Etnopsicologia. Metodologia qualitativa.

\begin{abstract}
Ethnography is a qualitative methodology that seeks to apprehend the way of living and the experiences of the people, which may benefit the research on religiosity/spirituality $(\mathrm{R} / \mathrm{S})$ in reference communities. The objective of this study was to narrate the ethnographic experience of a researcher in the field of $\mathrm{R} / \mathrm{S}$ visiting a mosque located in the interior of the State of São Paulo, discussing her impressions and dialogues with her own empirical field. The methodological strategies used were direct observation and the field diary. The narrated ethnographic experience can be useful to enter a reality in order to avoid generalizations at first sight, expressing from the descriptive lens of the researcher, in order to articulate it with existing knowledge and/or to produce new ones. In dialogue with ethnopsychology, the importance of maintaining a posture of alterity was emphasized in order to understand the religious universe of Muslims and reflect on how R/S is present in their personal experiences and behaviors. Finally, it is considered that ethnography is not the result of one going to the field, but of several comings and goings to the field, to the texts and the different

1 Mestre em Psicologia pela Universidade Federal do Triângulo Mineiro. E-mail: vivianfcunha@gmail.com

2 Pós-doutorado pela Universidade de Oxford, Doutora em Antropologia pela Universidade de São Paulo (USP). Professora Associada do Departamento de Psicologia da Faculdade de Filosofia, Ciências e Letras de Ribeirão Preto da Universidade de

3 Doutor em Psicologia pela Universidade de São Paulo (USP). Professor do Departamento de Enfermagem Psiquiátrica e Ciências Humanas da Escola de Enfermagem de Ribeirão Preto da Universidade de São Paulo (EERP-USP).
\end{abstract} São Paulo. 
universes involved, however, this exercise is fundamental to the researcher in the R/S field.

Keywords: Religion. Spirituality. Ethnopsychology. Qualitative methodology.

\section{Introdução}

No I Simpósio Nacional de Etnopsicologia, realizado em novembro de 2016 na Faculdade de Filosofia, Ciências e Letras de Ribeirão Preto da Universidade de São Paulo, o Prof. Dr. Maurício Neubern, da Universidade de Brasília, disse: "Não somos nós que escolhemos nosso campo, o campo nos escolhe". Para muitos pesquisadores dedicados e seus orientandos, essa é uma frase que conforta e dá sentido, pois são muitos os que se identificam com as inevitáveis circunstâncias que levaram a seus campos de pesquisas. Para pesquisadores que trabalham com as dimensões da religiosidade/ espiritualidade $(\mathrm{R} / \mathrm{E})$, isso é ainda mais presente, tendo em vista que as formações não abordaram diretamente essas questões, nos indicando, inicialmente, que não eram caminhos possíveis, principalmente na Psicologia.

Inicialmente, acatamos o positivismo presente em nossas formações, mas no meio de nossas histórias nos deparamos com uma incontestável porção que saltou aos olhos, colocando em evidência esse campo como foco também presente nas subjetividades humanas, nos direcionando para algo que sempre existiu. A partir daí fomos impulsionados a sair do mainstream da Psicologia e olhar para estudos que envolvem a Etnopsicologia e a Psicologia da Religião, por exemplo. Tornamosnos pesquisadores de $\mathrm{R} / \mathrm{E}$, abrindo a possibilidade para o divino, místico, sagrado, onde a fé e a relação das pessoas com ela viram alvos do nosso olhar e compreensão.

Os termos religião, religiosidade e espiritualidade são conceitos distintos e complexos. A sistematização dos mesmos e a discussão epistemológica que sustenta cada vertente que orienta a adoção de um ou de outro termo é igualmente complexa de ser empreendida. Ainda que não seja o objetivo deste estudo esclarecer as aproximações e os distanciamentos entre eles, pode-se didaticamente explicitar que a religião pode ser compreendida como uma instituição social composta por um sistema de crenças e práticas reunidas que sustentam uma suposta relação com uma dimensão transcendental e a religiosidade o modo pessoal de lidar ou vivenciar um sistema de crenças e práticas religiosas, que podem estar, ou não ligadas a uma instituição (CONSELHO REGIONAL DE PSICOLOGIA DE SÃO PAULO, 2015). Já a espiritualidade refere-se a um conceito mais amplo, ligado ao transcendente e ao sagrado, que pode, ou não, estar atrelado a uma religião (KOENIG, 2012). No entanto, optou-se por usar o termo combinado (R/E) sugerido pelas literaturas nacionais e internacionais, acreditando que há uma sobreposição entre esses conceitos, de maneira que podem ser intercambiáveis, em que qualquer definição não daria conta de abarcar sua complexidade (HILL et al., 2000; KOENIG, 2012; MARQUES, 2010; MOREIRA-ALMEIDA; KOENIG; LUCCHETTI, 2014).

Como pesquisadores desse campo, passamos a conviver com um estranhamento "positivo", já que é uma surpresa para a maioria das pessoas com quem conversamos informalmente, que trabalhamos com esse assunto de maneira científica. Muitas vezes nos vemos carentes de contato, de troca, de informação, porque apesar de ter outros pesquisadores no assunto, eles ainda são a minoria dentro da profissão. Por isso, estar nesse evento de Etnopsicologia foi uma conquista pessoal e também científica para os pesquisadores, pois muitas são as dificuldades de encontrar espaços para discutir temas que envolvem, por exemplo, as religiões, suas tradições e contextos, suas presenças na cultura e na subjetividade, a forma que se apresentam aos profissionais de Psicologia e suas possibilidades de atuação. Foi por esse interesse que nossos caminhos se cruzaram, desbravadores e seguidores, 
encantados pelos conhecimentos do campo que envolve $\mathrm{R} / \mathrm{E}$, em um país composto por $92 \%$ da população declarando ter uma religião, segundo os dados do IBGE (INSTITUTO BRASILEIRO DE GEOGRAFIA E ESTATÍSTICA, 2010).

Apesar de a Psicologia manter um esforço consistente de estudos da relação com a Religião por meio da "Psicologia da Religião", os estudos da etnopsicologia a respeito de religiões e culturas específicas também são encontrados na atualidade. Para Pagliuso e Bairrão (2011), o objetivo da etnopsicologia tem sido o de investigar a maneira como variados grupos étnicos administram conflitos, vivenciam as emoções e os relacionamentos interpessoais, dependendo do objetivo de cada pesquisador. Nesse processo, uma atenção especial tem sido dedicada às terminologias e ao sistema de compreensão do outro para perceber até que ponto o que está sendo nomeado pelo pesquisador de uma determinada forma corresponde à autocompreensão sistêmica do outro.

De acordo com Scorsolini-Comin (2014), o trabalho do etnopsicólogo assemelha-se ao do antropólogo, onde há necessidade de "estar dentro" da comunidade para poder vivenciála, compreendê-la e, posteriormente, analisá-la. Nesse âmbito, o olhar etnopsicológico instaura a necessidade de relativizar as distâncias entre o eu que analisa e o outro que é analisado, resgatando a importância de refletir sobre o modo como essa relação é construída, nutrida e também questionada ao longo trabalho (SCORSOLINI-COMIN, 2015a). Assim, uma maneira de se conhecer uma cultura ou comunidade pode ser a etnografia.

Para Rocha e Eckert (2008), o "estar dentro" permite o exercício do olhar (ver) e do escutar (ouvir), impondo ao pesquisador um deslocamento de sua própria cultura para se situar no interior do fenômeno observado através da sua participação efetiva, utilizando a observação direta como técnica privilegiada. Para Lima et al. (1996), o êxito deste tipo de investigação depende da sensibilidade do pesquisador diante das situações com as quais se depara e da interação que estabelece com a população em estudo.

Além disso, para Weber (2009), parte expressiva do ofício do etnógrafo reside na construção do diário de campo, sendo um instrumento que o pesquisador se dedica a produzir dia após dia ao longo de toda a experiência etnográfica, tendo por base o exercício de suas observações direta dos comportamentos culturais do grupo social. Bogdan e Biklen (1994) ressaltam que nos estudos de observação participante todos os dados são considerados notas de campo, que são as atribuições ao que o investigador ouve, vê, experiencia e pensa do decurso da coleta e reflexões sobre os dados de seu estudo. A etnografia é uma metodologia qualitativa que busca apreender a maneira de viver e as experiências das pessoas, aproximando-se ao máximo dos fenômenos, ampliando conhecimentos sobre o campo de estudo, o que pode beneficiar as pesquisas em torno da R/E. $\mathrm{O}$ objetivo deste estudo é narrar uma experiência etnográfica de uma pesquisadora na área da $\mathrm{R} / \mathrm{E}$, em visita a uma mesquita localizada no interior do Estado de São Paulo, discutindo suas impressões e diálogos com seu próprio campo empírico.

\section{O Desafio do Campo e do Método}

Parte dos requisitos de qualquer pesquisador é o aperfeiçoamento acadêmico, onde é exigido dos mestrandos ou doutorandos o cumprimento de créditos em seu currículo. Para a primeira autora, foi em uma disciplina de pós-graduação, como aluna especial do Programa de Pós-Graduação em Psicologia da Universidade de São Paulo, da Faculdade de Filosofia, Ciências e Letras de Ribeirão Preto, que teve seu primeiro contato com essa metodologia de investigação científica qualitativa, a etnografia. A partir desse momento, passa-se a narrar em primeira pessoa, buscando uma maior aproximação com a experiência a ser compartilhada neste estudo pela primeira autora. 
$\mathrm{Na}$ disciplina "Metodologias Qualitativas de Pesquisa", as docentes responsáveis, uma psicóloga e outra antropóloga, incentivaram uma aproximação ao nosso campo de estudo e pesquisa. Para isso seria importante exercitar uma escrita etnográfica, que me permitisse, segundo Mattos (2011), compreender pela observação direta e por um período de tempo as formas costumeiras de viver de um grupo particular, estudando os padrões mais previsíveis das percepções e comportamentos manifestos na rotina diária dos sujeitos. Ou, como destacam Lima et al. (1996), a etnografia é uma metodologia propícia para descobrir a maneira de viver e as experiências das pessoas - a sua visão do mundo, os sentimentos, ritos, padrões, significados, atitudes, comportamentos e ações, permitindo apreender o fenômeno na sua totalidade. Talvez essa totalidade não seja eficazmente possível, uma vez que o campo está sempre em movimento, mas, definitivamente, uma etnografia prestigia um olhar diferente e também importante.

A etnografia segue padrões ${ }^{4}$ que permitem desenvolver um trabalho a partir do campo no contexto social da pesquisa, onde essa metodologia parece levar maior contribuição para contextos de desigualdades sociais, processos de exclusão e situações sociointeracionais por motivos como: 1) preocupar-se com uma análise holística ou dialética da cultura; 2) introduzir os atores sociais com uma participação ativa e dinâmica, modificadora das estruturas sociais; 3) preocupar-se em revelar as relações e interações significativas de modo a desenvolver a reflexividade sobre a ação (MATTOS, 2011).

Apesar de a etnografia ter sua origem na Antropologia, suas contribuições enquanto método de pesquisa pode ser apreciada e utilizada em diversas áreas como na Educação Física (FARIA, 2014), na Saúde Pública (CASTRO-VIANEZ; BRANDÃO,
2015), em Políticas Públicas (FORELL; STIGGER, 2016) e Terapia Ocupacional (GALVANI et al., 2016), por exemplo. Na Psicologia, no que tange à dimensão da $\mathrm{R} / \mathrm{E}$, é possível encontrar trabalhos sobre a compreensão da literatura espírita (LEWGOY, 2004), da cura espiritual em casa afro-religiosa (TADVALD; MACEDO; SCALCO, 2015), na compreensão de diálogos e experiências de fé em grupos juvenis católicos (SOFIATI, 2012), sinalizando os potenciais de conhecimento que essa metodologia tem a oferecer.

Logo no começo da disciplina fui incentivada a manter um diário de campo para fazer anotações das minhas observações, notas em relação ao meu objeto de estudo, técnica que deixa claro que a Antropologia é uma forma científica de observação do sujeito. Nesse diário de campo eu tive a liberdade para registrar impressões, sentimentos e pensamentos que, futuramente, me permitiriam discorrer uma tentativa etnográfica para conclusão da disciplina. O que o caderno de campo registra é tudo aquilo que pode ser analisado, mas o bom pesquisador vai destacar dele o que for mais significativo para instrumentalizar a rede de significados. É a busca de significados, como diria Geertz (1978), que está em jogo. A descrição densa é justamente verificar essas camadas de significados que estão sobrepostas, no qual o pesquisador terá que fazer suas escolhas descritivas.

Apesar de pesquisar R/E em contexto clínico psicológico e, a todo o momento ter registros importantes sobre meu campo, como a minha própria experiência clínica ou informativos na mídia, estava longe da fase de coleta de dados, o que me permitiria discorrer mais profundamente sobre meu campo, me deixando sem saber o que de fato apresentar ao final do semestre. Angustiada, meu diário de campo retratava medos de não cumprir a tarefa, de não encontrar as sutilezas,

4 O primeiro deles é a relação. Não se produz etnografia sem a construção da relação com os sujeitos de pesquisa. A diferença é que no método etnográfico temos que nos adequar aos sujeitos pesquisados e não o contrário. Adequar é saber como estar em campo e de que forma esta relação pode, a miúde, ser construída. 
em não construir uma narrativa fluida, descritiva, qualitativa que pudesse dizer sobre o que estudo. Como destacado por Barbosa-Ferreira (2010), não basta uma observação participante ou uma escuta participante, é preciso ter um corpo participante para compreender o universo religioso, se permitir adentrar e conhecer os meandros deste universo em outras perspectivas. De acordo com Turner e Brunner (1986), a antropologia da experiência carrega em si a antropologia da performance e, mesmo com esses arcabouços teóricos, estamos sempre a construir textos fragmentados e borrados do que seriam ou sentiriam os nossos sujeitos pesquisados.

Todos os meus medos se concretizaram, pois nada do que idealizei no começo da proposta na disciplina se manteve, mas pude compreender que o campo pode ir além das quatro paredes de um consultório de Psicologia e encontrar espaço através de um convite inusitado, ao qual serei eternamente grata pela oportunidade, que foi conhecer uma Mesquita em Barretos, cidade do interior paulista. Essa experiência me permitiu refletir sobre a fé, religião, o sentido que tem na vida das pessoas, além de me aproximar do meu campo e ampliar minhas compreensões sobre a metodologia etnográfica, mostrando-me outras formas de fazer pesquisa que não as mais psicométricas. Como Barbosa-Ferreira (2009a), procurei até aqui não me desvincular dos afetos e do que realmente me afetava diante desse trabalho e acredito que essa apresentação sobre o percurso é importante para poder contextualizar as dificuldades no processo etnográfico e da compreensão final do campo.

Nesse tipo de trabalho de campo, os métodos e procedimentos envolvidos podem ser construídos pelo pesquisador, de modo que a significação dada à rotina pelos atores sociais não tem qualquer compromisso com generalizações, mas pode servir para uma discussão aprofundada acerca do papel do pesquisador e dos desafios e potencialidades inerentes a uma situação de contato com um "outro estranho", em um contexto que guarda nuances que podem ser resgatadas (SCORSOLINI-COMIN, 2015a). Diante dos desafios metodológicos, inspirada pelo trabalho realizado na disciplina, pelo convite que recebi, pelos aprendizados e reflexões desse campo, apresento uma visita realizada a uma Mesquita, no interior paulista.

\section{A Caminho de Allah}

Era véspera da viagem e recebi um convite "de última hora" para acompanhar um grupo de estudantes de Psicologia para uma visita na Mesquita de Barretos. Imediatamente aceitei. Acordei cedo, me arrumei e no medo de atrasar saio de casa sem o celular, não só um meio de comunicação na atualidade, mas uma forma de registrar imagens e áudios dessa experiência. Não dava tempo de voltar, então tive que encarar que essa experiência ficaria registrada apenas na minha memória, através das minhas observações e impressões, no meu diário de campo.

Pontualmente, o ônibus saiu para seu destino e no percurso começo a missão de registrar tudo que me parece importante e pertinente, tentando aproveitar ao máximo a experiência. Saímos da cidade de Ribeirão Preto e, como típico da região, era um dia quente, mesmo sendo início da primavera era possível ver que os campos ainda não estavam verdes devido à falta de chuva. Observo pela janela a cidade de Pitangueiras, com seu Cristo Redentor de braços abertos, recebendo os habitantes na entrada da cidade, à beira da pista.

Dentro do ônibus o ar condicionado era preciosidade diante do sol escaldante e do calor que fazia lá fora. No vidro que separava o motorista e eu, um adesivo grudado que dizia: "Propriedade exclusiva de Jesus". Tanto o Cristo na beira da estrada como o adesivo no ônibus me lembraram das constatações de que o Brasil representa um contexto social fortemente influenciado por tradições religiosas, crenças e experiências místicas, em um panteão diverso e multifacetado (BAIRRÃO, 2004) 
e que a cultura brasileira foi construída na tradição católica popular portuguesa, onde a religiosidade sempre incluiu aspectos que foram difundidos na vida social (ZACHARIAS, 2010). Esses elementos religiosos no trajeto confirmavam a inevitável presença da influência cristã sofrida pela nossa colonização e o quanto a dimensão religiosa permeia a vida das pessoas, fazendo parte do mundo e da cultura, e eu estava a caminho de outra, o Islã.

Ao chegar em Barretos, nas proximidades da Mesquita, a segunda construída no Brasil, já foi possível observar seu Minarete ${ }^{5}$. Barretos é uma cidade do interior paulista, localizada a $40 \mathrm{~km} \mathrm{da}$ divisa com Minas Gerais e por isso sofre influência cultural dos dois estados. De acordo com site do IBGE a cidade possui por volta de $112 \mathrm{mil}$ habitantes e dados do último Censo Demográfico (INSTITUTO BRASILEIRO DE GEOGRAFIA E ESTATÍSTICA, 2010) revelam que são cerca de 35 mil os seguidores do Islã no Brasil. Uma curiosidade sobre a Mesquita é que foi construída na década de 1960, sendo a primeira no interior paulista e, para mim, uma informação que nunca tive acesso antes, mostrando o meu desconhecimento dessa comunidade religiosa.

Um dos requisitos exigidos para entrada das mulheres na Mesquita foi a obrigatoriedade do uso do véu ou lenço na cabeça, deixando de fora apenas o rosto, mãos e pés. Por ser mulher, tive que me adaptar à situação e me colocar na posição de alteridade. Ver aquele grupo de estudantes, predominantemente feminino, foi por um momento "engraçado", percebendo o quanto somos "desengonçadas" ao trajar nosso lenço, que a toda hora precisava ser ajeitado, escorregando de nossas cabeças. Ao mesmo tempo, me permitiu vivenciar um símbolo muito importante dentro da comunidade islâmica.

Estar e me sujeitar a essa posição me remeteu a Bairrão (2004), que defende que a experiência religiosa não é uma questão de teses, nem de conceitos e muito menos de crenças, pois o verdadeiro religioso não crê, conhece, não havendo fé sem conhecimento. Portanto, a articulação mínima inarredável do fenômeno religioso parece consistir numa condição de presença e alteridade, já que não há como descartar a participação do fiel na sua experiência do sagrado, também não seria possível para o pesquisador implicado nesse estudo.

Apesar de o Islã ser lembrado cotidianamente nos noticiários por supostos envolvimentos em conflitos religiosos, as vestes femininas também são comumente alvo de atenção, onde há opiniões de uma repressão e desvalorização da mulher nessa população, ideia totalmente desconstruída por Barbosa-Ferreira (2013) em seu artigo sobre diálogos sobre o uso do véu. Confesso que posso ter cogitado essa possibilidade, acredito que a ignorância dá abertura para julgamentos sem fundamentos e precipitados, o que é pertinentemente explicado por Edward Said, em sua obra "Orientalismo: o Oriente como invenção do Ocidente". Sua ideia principal é mostrar a visão que o Ocidente tem sobre o Oriente e como essa visão pode ser equivocada, distorcida, denegrida, idealizada ou criada (SAID, 1990). Há que se ponderar que os estereótipos em relação aos muçulmanos estão levando à crescente islamofobia e, por isso, muitas mulheres no Brasil estão retirando o lenço por causa do preconceito e por não conseguirem emprego em suas áreas de trabalho.

Nessa experiência com o véu pude compreender melhor a expressão e o papel das vestimentas muçulmanas, que hoje acredito ser subjulgado pela grande maioria que não conhece o Islã. Ao vesti-lo pude perceber que existe uma mulher a ser preservada, uma feminilidade a ser cultivada e um apreço ao corpo, em que a mulher muçulmana tem uma posição definida, mas não determinante. Suas vontades, desejos e liberdade são resguardados e suas vestes são uma escolha, parte de um contexto

4 O minarete é uma torre fina e alta, geralmente localizada num dos cantos do complexo da mesquita, sendo, geralmente, seu ponto mais alto, não só da mesquita, mas também o ponto mais alto de toda a região em que se situa. 
cultural que pode ser mais ou menos exigente. No Brasil, a maior parte das muçulmanas não usa o lenço no cotidiano, o que pode ser observado ali mesmo, pelas muçulmanas que ao saírem da Mesquita tiraram suas vestes. A comunidade de Barretos é muito pequena, sendo que hoje muitos revertidos praticam mais seriamente a religião do que os nascidos muçulmanos. Neste contexto, sinto que a maior desvantagem do lenço foi suportar o calor da região e os olhares de estranhamento de quem passava na rua. Essa vivência foi particularmente marcante e acredito que o papel da mulher nessa comunidade merece destaque, mas tratarei essa questão de modo mais sintético, por uma opção metodológica. Para uma abordagem mais profunda do tema recomendamos a obra de Barbosa-Ferreira (2010).

Ao adentrar a Mesquita pude observar uma arquitetura própria e uma imensa cúpula no teto dava amplitude e fazia com que o espaço parecesse ainda maior. No salão poucas cadeiras, mas um grande espaço acarpetado, tendo em vista as prostrações feitas durante a reza e que os muçulmanos rezam em tapetes. Foi necessário deixar os sapatos na entrada, requisto para todos, mas que se mostrava pertinente diante dos armários para guardá-los e pela limpeza do chão. Parte do salão era dividido por esses armários, a direta dele era o espaço destinado à reza das mulheres e a esquerda, dos homens. Em meio às luminárias que caiam do alto do teto, pode-se ver a presença de lâmpadas de LED. As paredes eram claras, em tom de bege e branco, não tinham nenhuma imagem, apenas alguns quadros com escrita árabe. Humildemente, diante do grande salão, a direita do mirabe ${ }^{6}$, um púlpito (minbar) ${ }^{7}$ de madeira, utilizado mais tarde para realizar o culto.

Fomos recebidos pelo presidente da Mesquita com uma palestra muito esclarecedora para os leigos do Islã como eu. Foram apresentados seus pilares de fé, o que caracteriza um muçulmano, assim como, seus deveres básicos. Essas informações foram essenciais para compreender os muçulmanos, seu modo de vida e comportamentos. Subtende-se que a abertura para nos receber é um consentimento por parte da autoridade responsável, de maneira que essas informações possam ser veiculadas, dispensando sua submissão ao conselho de ética por se trata de um único encontro e de uma etnografia. Além disso, a segunda autora do artigo mantém sólido vínculo de pesquisa com a comunidade em questão. Nesse momento foi dada a oportunidade para fazermos perguntas, de entender melhor qual é a visão professada por essa religião e, timidamente, começou o questionamento.

\section{Meca $^{8}$ dos Meus Sonhos}

Nas últimas duas décadas, o contexto acadêmicocientífico tem apresentado um crescimento de produção científica relacionada às temáticas da $R / E$ evidenciando sua importância (FREITAS, 2014). De acordo com Aletti (2012), novas possibilidades são abertas pelos psicólogos da religião ao interagir com especialistas dos âmbitos vizinhos, sendo oportuno considerar diferentes e específicas contribuições considerando o homem como uma unidade biopsicossocial. A partir daí, houve uma consolidação dos interesses pelo tema das relações entre $\mathrm{R} / \mathrm{E}$ às características da personalidade, saúde, bem-estar físico e mental, na psicoterapia e pela visão funcional da religião, entendida como instrumento de coping (enfrentamento) para situações adversas e estressantes.

A etnopsicologia também traz muitas contribuições importantes ao olhar para o sujeito dentro de seu contexto cultural, permitindo

\footnotetext{
6 Nicho ou recinto semicircular ou poligonal, de teto abobadado. Tem como função indicar a direção da cidade de Meca, para qual os muçulmanos se orientam quando realizam as cinco orações diárias. Meca é a cidade sagrada para os muçulmanos, pois foi onde os primeiros versos do Alcorão foram revelados.

7 Composto por uma escadaria que leva a um estrado descoberto, utilizado pelo Sheik para professar o sermão da sexta-feira.

8 Cidade da Arábia Saudita, situada na província homônima.
} 
compreensões que podem ser erroneamente generalizadas ou confundidas com patologias ou transtornos mentais. Os transes mediúnicos e de possessão, comuns nas cerimônias de religiões de matriz africana como a umbanda e o candomblé, são exemplos que, por vezes, ao longo do tempo, foram associados a sintomas/expressões similares aos de alucinação e delírio, tipicamente encontrados em pacientes com esquizofrenia. Assim, a patologização das expressões religiosas atravessa o modo como o modelo biomédico muitas vezes compreende tais manifestações. Para Bastide (2016), pesquisador pioneiro das religiões afro-brasileiras, esses fenômenos dentro da comunidade religiosa são compreendidos como comunicação e restauração de equilíbrio, conectando ao universo mítico e sobrenatural de seus praticantes. A diferenciação entre o que é patológico perpassa o contexto cultural, de maneira que o aspecto religioso já vem sendo considerado um diferencial diagnóstico desde revisão do terceiro DSM (Manual Diagnóstico e Estatístico de Transtornos Mentais) em 1987 (ALLMON, 2013). Por conseguinte, questões acerca da R/E são cada vez mais investigadas levando em consideração os aspectos positivos e negativos que essa dimensão pode repercutir na saúde física e mental (KOENIG, 2012).

Algo que me chamava atenção, antes mesmo de saber mais sobre o Islã, era a importância de Meca e o fascínio devocional que os muçulmanos têm pela peregrinação até lá. Isso me foi esclarecido a partir do momento que compreendi, através da palestra, que a peregrinação para Meca (Hajj) é um dos cinco deveres que um muçulmano pode e deve ter, sendo a peregrinação obrigatória ao menos uma vez na vida, se tiver boas condições físicas e financeiras.

De posse de uma maior compreensão e conhecimento sobre o fundamento e a importância de Meca, despertou em mim a curiosidade em saber a importância que essa experiência tem na vida dos sujeitos. Dessa forma, na breve oportunidade que tive indaguei para aquele receptivo muçulmano que se dispôs a responder minhas perguntas:
Pergunta: Já teve a oportunidade de ir para Meca?

Resposta: Sim, já. Fui em 2014.

Pergunta: Como foi para você?

Resposta: Nossa, foi incrivel...

Sua resposta foi além do sonoro emitido por suas palavras. Pude perceber na sua expressão um encantamento com a experiência e oportunidade, algo que o deslumbrava diante de uma realidade cotidiana que muitas vezes parece cruel e egoísta, tendo em vista que para ele esse foi um momento de tranquilidade, onde se sentiu acolhido e identificado com aqueles que também se encontravam em jornada, pessoas de todos os tipos e países. É comum que as pessoas chorem quando se referem à peregrinação, pois a experiência costuma ser catártica. Relatou uma experiência única, onde viu igualdade, ordem e cooperação, diante do fato de que são milhares de peregrinos em trânsito até a "Mesquita Sagrada", seja dia ou noite. Sentiu-se em segurança o tempo todo e não faltou nada diante da grande quantidade de gente. Um dos pontos que devem ser trabalhados pelos muçulmanos em Meca é a paciência ( $\mathrm{sabr}$ ), pois tendo milhares de pessoas presentes, é mister exercer a paciência e a devoção.

Apesar de estimulado pelas minhas perguntas, ao relembrar nossa interação, associo esse momento a Favret-Saada (1990/2005), onde o que me parece ser comunicado é a intensidade do outro afetado, onde as imagens que, para ele e somente para ele, estão associadas a essa intensidade que escapam a esse tipo de comunicação. A partir daí, senti a necessidade de entender melhor essa experiência e descobri que são cerca de 3 milhões os peregrinos muçulmanos que vão ao Hajj, ao ano. A fé e seu dever para com ela mobiliza todos esses sujeitos ao mesmo lugar, mostrando a influência da cultura religiosa sobre a singularidade. Em setembro de 2015 foi registrado um incidente nessa região que deixou mais de 700 peregrinos mortos e 800 feridos (CONFUSÃO..., 2015), retratando outra faceta 
dessa jornada. No entanto, há que se considerar que há pessoas que relatam o "sonho" de morrer em Meca, devido ao caráter sagrado da cidade.

O relato do Presidente da Mesquita revela, simultaneamente, a presença da cultura e da singularidade no fenômeno religioso, onde se encontra a experiência coletiva e a vivência particular. Nesse sentido, escolher entre a figura e fundo dessa questão é que diferencia as possibilidades de atuação do profissional de Psicologia. Não compete ao psicólogo questionar os deveres postulados pelo Islã ou de qualquer religião, mas se atentar para a função e sentido que a experiência religiosa ganha através do sujeito. Fato ressaltado pela potencialidade transformadora da experiência religiosa nas trajetórias de vida dos sujeitos e de suas redes sociais, em que os sistemas religiosos fornecem recursos simbólicos para uma reorientação dos modos de existência e de seus sentidos (BIZERRIL; NEUBERN, 2012).

Isso não compromete o princípio de laicidade proposto pelo código de ética profissional, tendo em vista que o GT Nacional "Psicologia, religião e espiritualidade", ligado ao Conselho Federal de Psicologia (CFP) (CONSELHO FEDERAL DE PSICOLOGIA, 2013), afirma que pautar-se na obrigatória laicidade não implica negar uma interface que pode ser estabelecida pela Psicologia e a religião, e pela Psicologia e a espiritualidade, tendo em vista que a religião é um dos elementos mais complexos e irredutíveis da tessitura das culturas e aborda a relação das pessoas com aspectos transcendentais da existência (SCORSOLINI-COMIN, 2015b). Dessa forma, questionar e abordar $\mathrm{R} / \mathrm{E}$ no atendimento clínico psicoterápico não é proibido, nem antiético, estamos resguardos pelo empenho de um CFP que vem discutindo isso mais veemente, como podemos ver na coleção "Psicologia, Laicidade e as Relações com a Religião e a Espiritualidade", lançada em 2016, pelo Conselho Regional de Psicologia de São Paulo.

Compreender a $\mathrm{R} / \mathrm{E}$ vivenciada por cada um é fazer um resgate histórico e cultural que pode auxiliar na construção do sentido, permitindo uma construção social da sua relação com a fé. No caso da experiência de Meca, me foi necessário compreender minimamente o Islã, seus pilares de fundamentação e deveres, para atingir a compreensão da importância que mobiliza tanta gente. E, ainda, me foi importante questionar a experiência particular vivenciada por um muçulmano, constatando sua importância pessoal e quebrando preconceitos, para que pudesse ler a trágica notícia que matou mais de 700 pessoas, desconstruindo o viés religioso e atribuindo o caráter de fatalidade, que poderia ter acontecido em outras situações de aglomeração. Mas, apesar de não colocar a responsabilidade pelo acidente sobre a $\mathrm{R} / \mathrm{E}$, não posso deixar de salientar que foram as motivações religiosas que levaram os falecidos a esse lugar. Isso retoma a importância que a R/E exerce sobre o indivíduo, norteando através de seus símbolos, crenças e dogmas uma forma existir, constituindo sua subjetividade.

Apesar de não apresentar nenhuma relação direta com a psicoterapia, meu campo de pesquisa, é sob a importância que a $\mathrm{R} / \mathrm{E}$ exerce sobre o indivíduo que tais compreensões sobre Meca me levam a pensar melhor os significados dessa comunidade e me permite refletir sobre sujeitos religiosos, entendendo que é a construção de significados a partir do próprio sujeito que vão permitir compreender também as questões relativas à saúde e a doença, pois, como lembra Thomas (1970), quando alguém acredita que algo é real, ele se torna real nas suas consequências. Ou seja, a R/E de um paciente/cliente também influencia em como esse sujeito se relaciona com o mundo, de maneira que, inevitavelmente, essa dimensão está presente no contexto psicoterápico e não deve ser desconsiderada, mas sim levado em conta os interesses e vontades dos pacientes/ clientes (CUNHA; SCORSOLINI-COMIN, no prelo). Meca continua a me fascinar por representar e mobilizar tanto na vida dos muçulmanos. Para uns é a experiência dos sonhos, para outros, foi o pesadelo. 


\section{O Culto, o Sheik ${ }^{9}$ a Reversão}

A Salat (oração) é outro pilar que constitui o dever de um muçulmano e acontece diariamente, cinco vezes (BARBOSA-FERREIRA, 2009b). Após a palestra e aos vários questionamentos respondidos pelo Presidente da Mesquita, esse deu abertura para o Sheik realizar o culto da sexta-feira, uma celebração diferenciada porque a sexta-feira (Salat jummah, oração de sexta-feira) é um dos dias resplandecente do Islã e dia de congregação dos muçulmanos. Por ser um dia especial, deve ser feita exclusivamente na Mesquita, juntando a comunidade, ao meio-dia, onde são transmitidos ensinamentos, conselhos e orações.

As mulheres foram destinadas à sua ala, e então se deu início ao culto ${ }^{10}$, em árabe, dificultando o entendimento, mas permitiu ver a coerência da religião, uma vez que qualquer tradução do Alcorão (livro sagrado, original em Árabe) não é fidedigna e pode dar margem a interpretações distorcidas. Há que se considerar que o árabe tem expressões que não existem em outras línguas, por isso, se considera que são os significados do Alcorão e não o Alcorão em si. A essa altura o número de fiéis era maior e, predominantemente, masculino. Uma tentativa de tradução e disseminação das palavras do culto foi feita pelo Presidente da Mesquita, levantando os ensinamentos daquele dia, após a celebração.

$\mathrm{O}$ culto durou cerca de 50 minutos e, depois do encerramento, almoçamos ali mesmo, o próprio Sheik tinha feito lanches e quitutes árabes, demonstrando suas habilidades como excelente cozinheiro. Diferentemente de um padre, o Sheik é casado e com filhos, um deles percorria a Mesquita entre nós, tinha por volta de dois anos. Sua esposa era a única das mulheres na Mesquita que vestia a niqab ${ }^{11}$ em tempo integral, mesmo não sendo obrigada a trajá-la aqui no Brasil, não quis deixar esse costume de lado, apesar de ter conversado com várias pessoas a respeito disso. A presença desse Sheik é recente no Brasil, pois é refugiado sírio, e na Mesquita está há uns dois anos, já que o antigo voltou para o Egito. Natural da Síria, ele não fala muito bem o português.

Depois do lanche, sentamos no carpete e fizemos uma roda de conversa para discutir a experiência, trocamos impressões e opiniões. Um jovem, com seus vinte e poucos anos, que nos acompanhava desde que chegamos, contou sua história, ele era um muçulmano convertido. Seu interesse espiritual surgiu aos 17 anos, quando viu uma amiga acordar muito cedo, por volta da cinco da madrugada, para rezar (a primeira oração do dia dos mulçumanos, Fajr, acontece antes do amanhecer). Curioso com sua devoção resolveu pesquisar mais sobre o Islã. Nessa busca consultou outras religiões, mas encontrou no Islã uma verdade que faz sentido para sua vida e representa o que acredita, identificandose com suas crenças, valores e, desde então, começou a se informar mais sobre o assunto, a frequentar a Mesquita e decidiu declarar seus votos, assumindo-se como muçulmano. Qualquer um pode se reverter e se tornar muçulmano, mas para isso é importante declarar os votos e dar seu testemunho de fé, acreditando em Deus único (Allah) e no seu Mensageiro - Profeta Muhammad, o primeiro pilar que fundamenta a religião.

Informações na mídia vêm apontando que o número de muçulmanos convertidos tem aumentado e que, no futuro, essa será a maior religião do mundo. Bizerril e Neubern (2012) nos lembram de que a singularidade do indivíduo não se restringe a um processo puramente psicológico, uma vez

9 Líder religioso, responsável pela manutenção das Mesquitas, realizar casamentos e sessões de orações.

${ }^{10}$ Sermão não é recitado, apenas o Alcorão. Há mesquitas em que o sermão acontece em árabe e após tem a tradução, como no caso de Barretos. Há outras em que o Sheik faz em português e árabe.

${ }^{11}$ Veste feminina, tradicional das mulheres muçulmanas, que cobre todo o corpo, deixando apenas os olhos com uma rede para poder enxergar. As mulheres do Profeta Muhammad usavam para serem diferenciadas das demais. Algumas mulheres acham isso necessário, mas não é regra da religião. O uso é opcional. No caso da esposa do Sheik, ela usa desde os 15 anos, tem mais de 17 anos usando, não conseguiu tirar mesmo estando em Barretos-SP, que faz um calor significativo. 
que é perpassada por registros sociais, políticos, econômicos, institucionais, culturais e religiosos que são subjetivados de acordo com a ação do sujeito no mundo. Retomando os recentes acontecimentos sociais, políticos e econômicos, podemos observar um caos provocado pela transformação da ordem internacional, levando a um regresso a experiência religiosa na busca de sentido para confusão geral (OLIVEIRA, 2013).

Outra forte evidência da importância e crescimento do Islã é o aumento de publicações e preocupação acadêmica acerca da sua relação com a saúde mental no Oriente Médio, onde está a maior parte dos muçulmanos (KOENIG; ZABEN; KHALIFA, 2012). Além disso, devido às particularidades em relação às suas crenças e comportamentos, pesquisas consideram recomendações psicoterápicas específicas voltadas para esse público, atribuindo maneiras de integrar sua R/E na psicoterapia (ABU-RAIYA, 2015; ABURAIYA; PARGAMENT, 2010). Isso não significa que devemos nos especializar em uma psicoterapia voltada para os muçulmanos ou qualquer outra religião, muito menos supervalorizar essa dimensão, mas é importante respeitar e estar aberto para que esses conteúdos tenham vazão, sejam acolhidos e se tornem alvos de reflexão, se necessário. Como sugere Scorsolini-Comin (2015b), é preciso compreender os significados de seus relatos e de que modo esse sistema de referências está cravado no psiquismo do paciente/cliente.

Antes de ir embora, o Sheik, que estava nos fazendo companhia, observando nossa conversa, passou a fazer um discurso de agradecimento. Em um português que foi difícil entender começou a dizer que Allah nos convidou, foi ele quem quis que estivéssemos ali, foi Allah quem permitiu nosso encontro, ressaltando seu contentamento pela oportunidade de mostrar um pouco da sua religião. Com um sorriso no rosto de satisfação disse que as portas estavam sempre abertas. Após essas palavras, descobertas mais tarde que foram raras diante de sua dificuldade com o idioma, partimos de volta para Ribeirão Preto.

Dentro do ônibus processo toda a experiência, pensando na possibilidade de transformá-la no meu trabalho para disciplina e em como me senti tocada por esse campo. Entre meus pensamentos e anotações no diário de campo olho pela janela, lá está novamente o Cristo Redentor ${ }^{12}$ com seus braços abertos, não mais em Pitangueiras, mas em Sertãozinho, no alto de uma colina, como quem, de cima, abençoa a cidade. Lembro imediatamente do convite de Allah para nosso encontro - palavras do Sheik-, das circunstâncias que me levaram a essa experiência e do que escolhi estudar. Todos esses movimentos são partes de uma representação social do divino, do sagrado, parte de uma dimensão religiosa/espiritual que, implícita ou explicitamente, não podem ser desconsideradas ou subjugadas no "fazer" da prática clínica de psicoterapeutas (PARGAMENT, 2007).

Foi o meu primeiro contato com a Mesquita, breve, mas muito intenso. Imprimiu-me revelações pessoais, profissionais e enquanto pesquisadora. Nessa última instância, percebo-me mais sensível às divergências culturais, onde o fenômeno religioso está presente na individualidade e na esfera coletiva, sinalizando a dualidade entre a complexidade e a naturalidade do ato de crer. A partir dessa dimensão pode-se compreender a relação em comunidade, da questão homem-mulher, de seu posicionamento como mãe-pai, de valores morais e do engajamento nela. Para os muçulmanos a religião tem papel central e fundamental em suas vidas e, nesse sentido, a experiência religiosa induz ou produz um estado psicológico conveniente à sua manifestação, onde a Psicologia é convocada a desvendar o religioso (BAIRRÃO, 2004).

\footnotetext{
12 Para os muçulmanos, Jesus foi um profeta e não foi crucificado, ele foi arrebatado de corpo e alma para o céu e um dia voltará. No Islã não "somos" filhos de Deus, mas criaturas Dele.
} 
Por ser uma tentativa de observação holística dos modos de vida das pessoas, a etnografia permite outra maneira de conhecer os fenômenos (MATTOS, 2011), saindo dos métodos "mais conhecidos" na Psicologia. Nesse sentido, o método pode beneficiar as pesquisas em torno dessa temática, ampliando conhecimentos sobre o campo de pesquisa sobre $\mathrm{R} / \mathrm{E}$, respeitando e levando em conta o seu contexto cultural. Dessa maneira, não se tem pretensão de esgotar o assunto ou produzir uma verdade, até mesmo porque há limitações diante do método, mas o principal objetivo desse estudo foi explorar, a partir de uma experiência etnográfica, a produção de um material que pode contribuir para reflexões e discussões sobre estudos voltados para R/E, mais especificamente, o Islã.

\section{Considerações Finais}

Estudar o campo da R/E exige abertura e alteridade, muitas vezes o profissional pode ser descaracterizado enquanto cientista por falar sobre esse mundo, onde parece não haver lugar na formação profissional para esse assunto, muitas vezes hostilizados e tidos como rivais. Nesse sentido, avanços já são encontrados e, paulatinamente, as pesquisas nacionais retratam a presença dessa hostilidade e dificuldade, mas incrementam o repertório de estudos mostrando possibilidades de atuação aos profissionais.

Sobre esse aspecto, este estudo pretende expor que há maneiras variadas de se abordar a temática através da Psicologia, sendo a etnografia uma forma de observar o modo como os grupos ou pessoas conduzem suas vidas com o objetivo de revelar o significado cotidiano nos quais as pessoas agem, documentando, monitorando e encontrando significados a partir da participação e observação. Dessa maneira, a etnografia se mostra um potencial metodológico qualitativo, capaz de aprofundar e descrever cenários que podem auxiliar a quebrar preconceitos, ampliando e apresentando a realidade a partir de diversos contextos, aproximando o leitor e, consequentemente, sensibilizando para novas formas de apreender os fenômenos. No entanto, como qualquer metodologia, possui limites e desvantagens, suscitando questionamentos quanto aos cuidados éticos, principalmente a partir de exigências no campo de pesquisa em saúde.

Diante disso, considera-se que a experiência etnográfica permite exprimir a realidade sob a luz descritiva do pesquisador, de modo a articulá-la com conhecimentos existentes e produzir novos. Cabe ao pesquisador preservar a cientificidade e os cuidados éticos, mas nem por isso perder uma postura de alteridade indispensável. Essa mesma postura é requerida ao psicólogo clínico, de modo que a cada encontro é um novo desconhecido. Na compreensão subjetiva de um paciente/cliente, pensando no caso dos muçulmanos, é indispensável compreender seu universo religioso, identificando suas experiências pessoais, místicas e comportamentos que se apresentam mais ou menos relevantes em suas vidas. Nesse sentido, faz-se importante ampliar a discussão da importância da R/E nos atendimentos psicológicos, do aumento das pesquisas realizadas com esse tema, das implicações que tem para a saúde, do impacto e particularidades na vida dos sujeitos, como no caso dos muçulmanos.

Sabe-se que não foi possível apresentar uma grande visão de mundo, de sentimentos, atitudes, comportamentos e ações que representam a totalidade dessa comunidade religiosa, muito menos pensar em generalizações. Mas o convite de Allah foi irresistível e sensibiliza para uma abertura ao Islã, da importância que a religião imprime na individualidade e na sociedade e da nossa responsabilidade de sermos sensíveis para percebêla e abordá-la.

\section{Agradecimentos}

Os autores agradecem à leitura inicial do texto por parte da Profa. "Dra. Clarissa Mendonça Corradi-Webster", do Programa de Pós-graduação 
em Psicologia da Faculdade de Filosofia, Ciências e Letras de Ribeirão Preto da Universidade de São Paulo. Este relato de experiência foi entregue para a conclusão da disciplina de "Metodologias Qualitativas de Pesquisa", oferecida como eletiva no referido programa e sob a responsabilidade da Profa "Dra. Clarissa Mendonça Corradi-Webster" e da Profa. "Dra. Francirosy Campos Barbosa". Agradecemos ao convite da Profa. "Dra. Francirosy Campos Barbosa" para a visita de campo, aqui narrada e discutida.

\section{Referências}

ABU-RAIYA, H. Working with religious muslim clients: a dynamic, qura'nic-based model of psychotherapy. Spirituality in Clinical Practice, New York, v. 2, n. 2, p. 120-133, 2015. Disponível em: <http://psycnet.apa.org/ fulltext/2015-21608-001.html>. Acesso em: 24 set. 2018.

ABU-RAIYA, H.; PARGAMENT, K. I. Religiously integrated psychotherapy with muslim clients: from research to practice. Professional Psychology: research and practice, New York, v. 41, n. 2, p. 181188, 2010. Disponível em: <http://psycnet.apa.org/ fulltext/2010-06890-014.html>. Acesso em: 24 set. 2018.

ALETTI, M. A psicologia diante da religião e da espiritualidade: questões de conteúdo e de método. In: FREITAS, M. H.; PAIVA, G. J. (Org.). Religiosidade e cultura contemporânea: desafios para a psicologia. Brasília: Universa, 2012. p. 157-190.

ALLMON, A. L. Religion and the DSM: from pathology to possibilities. Journal of Religion and Health, New York, v. 52, p. 538-549, 2013.

BAIRRÃO, J. F. M. H. Espiritualidade brasileira e clínica psicológica. In: ANGERAMI-CAMON, V. A. (Org.). Espiritualidade e prática clínica. São Paulo: Thomson, 2004. p. 193-214.

BARBOSA-FERREIRA, F. C. B. Diálogos sobre o uso do véu (hijab): empoderamento, identidade e religiosidade. Perspectivas: Revista de Ciências Sociais, Araraquara, v. 43, p. 183-198, 2013. Disponível em: <https://periodicos. fclar.unesp.br/perspectivas/article/view/6617/4864>. Acesso em: 24 set. 2018.

BARBOSA-FERREIRA, F. C. B. Mais de mil e uma noites de experiência etnográfica: uma construção metodológica para pesquisadores-performers da religião. Etnográfica - Revista do Centro em Rede de Investigação em Antropologia, Lisboa, v. 13, n. 2, p. 441-464, 2009a.
Disponível em: <https://journals.openedition.org/ etnografica/1166>. Acesso em: 24 set. 2018.

BARBOSA-FERREIRA, F. C. B. Olhares femininos sobre o Islã: etnografias, metodologias e imagens. São Paulo: Hucitec, 2010.

BARBOSA-FERREIRA,F.C. B. Teatralização do sagrado islâmico: a palavra, a voz e o gesto. Religião \& Sociedade, Rio de Janeiro, v. 29, p. 95-125, 2009b. Disponível em: $\quad<$ http://www.scielo.br/scielo.php?script=sci arttext\&pid=S0100-85872009000100005\&lng=en\&nrm =iso $>$. Acesso em: 24 set. 2018.

BASTIDE, R. Le rêve, la transe et la folie. Tradução de MOURA, C. E. M. O sonho, o transe e a loucura. São Paulo: Três Estrelas, 2016.

BIZERRIL, J.; NEUBERN, M. Experiência religiosa e subjetiva no contexto contemporâneo: diálogo entre psicologia e antropologia. In: FREITAS, M. H.; PAIVA, G. J. (Org.). Religiosidade e cultura contemporânea: desafios para a psicologia. Brasília: Universa, 2012. p. 231-260.

BOGDAN, R.; BIKLEN, S. Investigação qualitativa em educação: uma introdução à teoria e os métodos. Porto: Ed. Porto, 1994.

CASTRO-VIANEZ, P. S.; BRANDÃO, E. R. Desafios éticos, metodológicos e pessoais/profissionais do fazer etnográfico em um serviço público de saúde para atendimento aos transtornos alimentares na cidade do Rio de Janeiro. Saúde e Sociedade, São Paulo, v. 24, n. 1, p. 259-272, 2015. Disponível em: <http://www. scielo.br/scielo.php?script $=$ sci arttext\&pid $=$ S0104$12902015000100259 \& \operatorname{lng}=p t \& t \operatorname{lng}=p t>$. Acesso em: 24 set. 2018.

CONFUSÃO durante peregrinação: a Meca mata centenas na Arábia Saudita. G1, São Paulo, 25 nov. 2015. Disponível em: <http://g1.globo.com/mundo/ noticia/2015/09/tragedia-durante-peregrinacao-naarabia-saudita-mata-centenas.html >. Acesso em: 24 set. 2018.

CONSELHO FEDERAL DE PSICOLOGIA. Posicionamento do sistema de conselhos de psicologia para a questão da psicologia, religião e espiritualidade. Brasília, 2013.

CONSELHO REGIONAL DE PSICOLOGIA DE SÃO PAULO. Recomendações para atuação do profissional da(o) psicóloga(o): relatório síntese das discussões dos seminários estaduais psicologia, laicidade e as relações com a religião e a espiritualidade. 2015. Disponível em: $\quad<$ http://www.crpsp.org.br/diverpsi/arquivos/ Recomendacoes_Diverpsi.pdf $>$. Acesso em: 24 set. 2018 . 
CUNHA, V. F.; SCORSOLINI-COMIN, F. Religiosidade/ espiritualidade $(\mathrm{R} / \mathrm{E})$ no contexto clínico: experiências profissionais de psicoterapeutas. Temas em Psicologia, Ribeirão Preto. No prelo.

FARIA, E. L. Quando "rola a bola": reflexões sobre as práticas futebolísticas e a forma escolar nas aulas de Educação Física. Revista Brasileira de Ciência do Esporte, Porto Alegre, v. 36, n. 2, p. 501-513, 2014. Disponível em: $\quad<\mathrm{http}: / /$ www.scielo.br/scielo.php?script $=$ sci arttext\&pid $=$ S0101-32892014000200501\&lng=en\&nrm $=$ iso $>$. Acesso em: 24 set. 2018.

FORELL, L.; STIGGER, M. P. Gestão e democracia: um estudo etnográfico sobre a apropriação das políticas públicas de esporte e lazer no parque Ararigbóia em Porto Alegre/RS. Licere, Belo Horizonte, v. 19, n. 2, p. 168-198, 2016. Disponível em: <https://seer.ufmg.br/ index.php/licere/article/download/2048/1488>. Acesso em: 24 set. 2018 .

FREITAS, M. H. Religiosidade e saúde: experiências dos pacientes e percepções dos profissionais. Revista Pistis e Práxis: teologia e pastoral, Curitiba, v. 6, n. 1, p. 89-105, 2014. Disponível em: $<$ https://periodicos.pucpr.br/index. php/pistispraxis/article/view/13046/12473>. Acesso em: 24 set. 2018.

GALVANI, D. et al. Exercícios etnográficos como atividades em espaço público: terapia ocupacional social no fazer da arte, da cultura e da política. Cadernos de Terapia Ocupacional da UFSCar, São Carlos, v. 24, n. 4, p. 859-868, 2016. Disponível em: <http://www. cadernosdeterapiaocupacional.ufscar.br/index.php/ cadernos/article/view/1756/792>. Acesso em: 24 set. 2018.

GEERTZ, C. Uma descrição densa: por uma teoria interpretativa da cultura. In: GEERTZ, C. A interpretação das culturas. Rio de Janeiro: Zahar, 1978. p. 13-41.

HILL, P. C. et al. Conceptualizing religion and spirituality: points of commonality, points of departure. Journal for the Theory of Social Behaviour, Oxford, v. 30, p. 51-77, 2000. Disponível em: <https://onlinelibrary. wiley.com/doi/epdf/10.1111/1468-5914.00119>. Acesso em: 24 set. 2018.

IBGE. Censo demográfico - 2010. Rio de Janeiro, 2010.

KOENIG, H. G. Religion, spirituality, and health: the research and clinical implications. ISRN Psychiatry, London, v. 2012, 2012. Disponível em: <https://www. hindawi.com/journals/isrn/2012/278730/>. Acesso em: 24 set. 2018.

KOENIG, H. G.; ZABEN, F. A.; KHALIFA, D. A. Religion, spirituality and mental health in the West and the Middle East. Asian Journal of Psychiatry, Wilmington, v.
5, p. 180-182, 2012.

LEWGOY, B. Etnografia da leitura num grupo de estudos espírita. Horizontes Antropológicos, Porto Alegre, v. 10, n. 22, p. 255-282, 2004. Disponível em: <http://www. scielo.br/scielo.php?script=sci_arttext\&pid=S0104$71832004000200011 \& \operatorname{lng}=\mathrm{en \& nrm}=\mathrm{iso}>$. Acesso em: 24 set. 2018.

LIMA, C. M. G. et al. Pesquisa etnográfica: iniciando sua compreensão. Revista Latino-Americana de Enfermagem, Ribeirão Preto, v. 4, n. 1, p. 21-30, 1996. Disponível em: $\quad<$ http://www.scielo.br/scielo.php?script=sci arttext\&pid $=$ S0104-11691996000100003\&lng $=$ pt\&nrm =iso $>$. Acesso em: 24 set. 2018.

MARQUES, L. F. O conceito de espiritualidade e sua interface com a religiosidade e a psicologia positiva. Revista Psicodebate Psicología, Cultura y Sociedad, Ciudad de Buenos Aires, v. 10, p. 135-151, 2010.

MATTOS, C. L. G. A abordagem etnográfica na investigação científica. In: MATTOS, C. L. G.; CASTRO, P. A. (Org.). Etnografia e educação: conceitos e usos. Campina Grande: EDUEPB, 2011. p. 49-83.

MOREIRA-ALMEIDA, A.; KOENIG, H. G.; LUCCHETTI, G. Clinical implications of spirituality to mental health: review of evidence and practical guidelines. Revista Brasileira de Psiquiatria, São Paulo, v. 36, n. 2, p. 176-182, 2014. Disponível em: <http://www. scielo.br/scielo.php?script=sci_arttext\&pid $=\mathrm{S} 1516$ $44462014000200176 \& \operatorname{lng}=$ en\&nrm=iso $>$. Acesso em: 24 set. 2018.

OLIVEIRA, J. L. M. Influência da globalização no processo de conversão/desconversão religiosa: contribuições das ciências da religião. In: FREITAS, M. H.; PAIVA, G. J.; MORAES, C. (Org.). Psicologia da religião no mundo ocidental contemporâneo: desafios da interdisciplinaridade. Brasília: EdUCB, 2013. p. 419435.

PAGLIUSO, L.; BAIRRÃO, J. F. M. H. A etnopsicologia e o trabalho institucional em uma unidade de abrigo. Revista da SPAGESP, Ribeirão Preto, v. 12, n. 1, p. 43-55, 2011. Disponível em <http://pepsic.bvsalud. org/scielo.php?script=sci_arttext\&pid $=$ S 1677 $29702011000100006 \& \operatorname{lng}=\mathrm{pt} \& \mathrm{n} r \mathrm{~m}=\mathrm{iso}>$. Acesso em: 24 set. 2018.

PARGAMENT, K. I. Spiritually integrated psychotherapy: understanding and addressing the sacred. New York: The Guilford Press, 2007.

ROCHA, A. L. C.; ECKERT, C. Etnografia: saberes e práticas. Iluminuras, Porto Alegre, v. 31, 2008. Disponível em: <http://seer.ufrgs.br/iluminuras/article/ view/9301/5371>. Acesso em: 24 set. 2018. 
SAID, E. W. Orientalismo: o Oriente como invenção do Ocidente. São Paulo: Companhia das Letras, 1990.

SCORSOLINI-COMIN, F. "Ela não tem explicação, ela tem vida": a relação pesquisador-pesquisado no contexto de uma investigação etnopsicológica sobre mediunidade. Cultures-Kairós: Revue d'Anthropologie des Pratiques Corporelles e des Arts Vivants, [S. n.], v. 5, p. 1-17, 2015a. Disponível em: <http://revues.mshparisnord.org/ cultureskairos/index.php?id=1071>. Acesso em: 24 set. 2018.

SCORSOLINI-COMIN, F. Atenção psicológica e umbanda: experiência de cuidado e acolhimento em saúde mental. Estudos e Pesquisas em Psicologia, Rio de Janeiro, v. 14, n. 3, p. 773-794, 2014. Disponível em: $<$ http://www.e-publicacoes.uerj.br/index.php/revispsi/ article/download/13882/10602>. Acesso em: 24 set. 2018.

SCORSOLINI-COMIN, F. Elementos do aconselhamento multicultural aplicados à psicoterapia em contextos etnopsicológico. Estudos e Pesquisas em Psicologia, Rio de Janeiro, v. 15, n. 2, p. 587-607, 2015b. Disponível em: $\quad<$ http://pepsic.bvsalud.org/scielo.php?script=sci arttext\&pid=S1808-42812015000200009\&lng=pt\&nrm =iso $>$. Acesso em: 24 set. 2018.

SOFIATI, F. M. Etnografia de grupos juvenis católicos: diálogos e experiências de fé. Caminhos, Goiânia, v. 10, n. 1, p. 142-162, 2012. Disponível em: <http:// seer.pucgoias.edu.br/index.php/caminhos/article/ view/1979/1241>. Acesso em: 24 set. 2018.

TADVALD, M.; MACEDO, J. L.; SCALCO, L. M. Espiritualidade e cura: análise etnográfica da cura espiritual a partir de uma casa afro-religiosa da cidade de Porto Alegre (Brasil). Ciencias Sociales y Religión, Porto Alegre, v. 17, n. 22, p. 38-51, 2015. Disponível em: $<$ http://seer.ufrgs.br/CienciasSociaiseReligiao/article/ view/55598/35327>. Acesso em: 24 set. 2018.

THOMAS, W. The definition of situation. In: COSER, L. A.; ROSEMBERG, B. (Ed.). Sociological theories: a book of readings. Toronto: Mcmillan Company, 1970. p. 245-247.

TURNER, V.; BRUNER, E. (Ed.). The anthopology of experience. Urban: University of Illinois Press, 1986.

WEBER, F. A entrevista, a pesquisa e o íntimo, ou por que censurar seu diário de campo? Horizontes Antropológicos, Porto Alegre, v. 15, n. 32, p. 157-170, 2009. Disponível em: $\quad<$ http://www.scielo.br/scielo.php?script=sci arttext\&pid=S0104-71832009000200007\&lng=en\&nrm $=$ iso $>$. Acesso em: 24 set. 2018.

ZACHARIAS, J. J. M. Ensaio sobre psicologia e religião: uma questão do olhar. Psicólogo Informação, São Bernardo do Campo, v. 14, p. 171-180, 2010. Disponível em: $\quad<$ http://pepsic.bvsalud.org/scielo.php?script=sci arttext\&pid=S1415-88092010000100011\&lng=pt\&nrm =iso $>$. Acesso em: 24 set. 2018. 
